\title{
O MUSEU VIRTUAL DE OURO PRETO (MG) COMO FERRAMENTA DE COMUNICAÇÃO TURÍSTICA PARA A DESTINAÇÃO
}

BRENDO RODRIGUES DOS SANTOS UNIVERSIDADE FEDERAL DO PIAUÍ PIAUÍ, BRASIL BRENDORSANTOS5@GMAIL.COM

ANDRÉ RIANI COSTA PERINOTTO UNIVERSIDADE DO VALE DO RIO DOS SINOS SÃO LEOPOLDO, RIO GRANDE DO SUL, BRASIL PERINOTTO@UFPI.EDU.BR

HTTP://DX.DOI.ORG/10.5902/2316882X22791 


\section{O MUSEU VIRTUAL DE OURO PRETO (MG) COMO FERRAMENTA DE COMUNICAÇÃO TURÍSTICA PARA A DESTINAÇÃO}

Resumo: O presente artigo tem por objetivo abordar a temática dos museus virtuais, acarretando uma análise de como essas plataformas podem ser utilizadas para a comunicação turística dos destinos. Para a obtenção dos dados, foi utilizada a pesquisa bibliográfica, além de se realizar o estudo de caso de um museu virtual consolidado. Evidenciou-se que os museus virtuais podem ser utilizados para a promoção dos destinos turísticos, mesmo que indiretamente.

Palavras-Chave: Museus Virtuais; Comunicação Turística; Promoção dos Destinos

\section{EL MUSEO VIRTUAL DE OURO PRETO (MG) COMO HERRAMIENTA DE COMUNICACIÓN TURÍSTICA PARA LA ASIGNACIÓN}

Resumen: En este artículo se propone estudiar la temática de los museos virtuales y, por consiguiente, presentar un análisis de cómo estas plataformas pueden ser utilizadas para la comunicación turística de los destinos. Para obtener los datos, fue empleada la investigación bibliográfica, además de realizar el estudio de caso de un determinado museo virtual consolidado. Por lo tanto, se constató que los museos virtuales pueden ser usados para la promoción de los destinos turísticos, aunque de manera indirecta.

Palabras clave: Museos Virtuales; Comunicación Turística; Promoción de los Destinos

\section{THE VIRTUAL MUSEUM OF OURO PRETO (MG) AS A TOOL OF TOURIST COMMUNICATION FOR THE DESTINATION}

Resume: This article aims to address the theme of virtual museums, resulting in an analysis of how these platforms can be used for communication tourist of the destinations. To obtain the data, the bibliographic research was used, in addition to accomplish the case study of a consolidated virtual museum. It was evident that virtual museums can be used for the promotion of tourist destinations, even if indirectly.

Keywords: Virtual Museums; Tourist communication; Promotion of the Destinations 


\section{Introdução}

Turismo e museus adquiriram uma relação intrínseca, onde um depende do outro direta ou indiretamente, já que muitos museus precisam de visitantes para se manter, e o turismo necessita dos museus como um atrativo singular, pois, mesmo que existam diversos museus, cada um deles é diferente, cada um adequa-se à sua comunidade, à sua realidade.

Como o passar dos anos, essa relação causou mudanças de ambas as partes, onde o turismo passou a "educar" os visitantes, e os museus passaram a se adaptar à essas visitações, oferecendo uma experiência cada vez mais completa aos visitantes advindos do turismo, ou não.

Entretanto, os visitantes se tornaram cada vez mais exigentes, onde, não se contentavam mais em apenas ver as obras, não bastava a eles apenas contemplar os acervos, eles queriam mais, queriam interagir com as obras, entrar nos acervos, obter ainda mais informações, entre outras coisas. Diante desse panorama, os museus tiveram que se reinventar, utilizando-se da tecnologia para isso, utilizando-se do avanço tecnológico para se tornarem cada vez mais interativos e agradáveis aos seus visitantes e exploradores.

Como um dos resultados dessa evolução "tecnomuseológica", pode-se citar os museus virtuais, que podem ser museus inteiramente virtuais (não dependendo de um local físico), ou podem ser museus virtualizados, ou seja, uma cópia virtual de um museu físico/real.

No caso dos museus virtuais que são cópias de outros museus, sabe-se que esse tipo de museu virtual oferece informações sobre as localidades dos quais estão inseridos, informações que podem ser tratadas como confiáveis, já que tais informações são disponibilizadas com o intuito de aprendizagem, e não são de caráter promocional.

Portanto, o presente artigo tem como enfoque analisar a relação entre museus virtuais e a comunicação turística, ou seja, traz-se uma discussão a respeito das potencialidades dos museus virtuais como ferramenta da comunicação turística.

Para isso, utilizou-se de pesquisa bibliográfica sobre diversos temas, que vão desde a cibermuseologia à engenharia de trânsito. Além de se realizar um estudo de caso com um museu virtual já consolidado, que reflete bem o caso dos espaços que foram virtualizados para uma melhor visitação.

Rev.Cad.Comun. Santa Maria, v.20, n.3, art 5, p.99 de 123, set/dez.2016 
A partir disso, constatou-se que os museus virtuais podem sim ser uma ferramenta de comunicação turística, mesmo que indiretamente, já que os museus virtuais não surgiram com esse foco, surgiram da necessidade de interação entre acervo e visitante, e também como uma forma de preservação desses espaços.

\section{Turismo, cultura e museus}

A partir da percepção de que turismo e cultura são elementos transversais - e que se interagem - o Governo brasileiro passou a elaborar novas políticas onde ambos podem ser elementos complementares. Como apresenta Santos et. al. (2012, p. 5-6):

Turismo e Cultura tornam-se, hoje, no Brasil, objetos de políticas sistemáticas de médio e longo prazo sistematizadas em Planos Nacionais e outros documentos de diretrizes de ação. Paulatinamente, essas esferas iniciam um diálogo que constitui um campo de intersecção e ação entre elas, voltadas para a organização dos mercados, mas pautadas por marcas ideológicas no tocante às concepções de cultura e identidade, como se pode verificar no texto do Plano Nacional de Turismo 2003- 2007.

Igualmente, Lima et.al. (s/d, s/p) expõe que:

A Política Nacional de Museus também trabalha com a questão do Turismo, a fim de tornar os museus brasileiros em atrativos significantes. O investimento para a melhoria das instituições está focando primeiramente os museus das cidades-sede da Copa do Mundo 2014 a fim de prepará-los para receber visitantes durante esse período.

Como resultado desses investimentos para a copa: vários projetos de museus foram iniciados, por exemplo, o Museu do Amanhã, no Rio de Janeiro, surgiu como segunda opção para os visitantes da Copa durante os dias sem jogos e também poderá servir como um atrativo a mais durante as Olimpíadas do Rio.

Ainda sobre a relação entre turismo - cultura - museus, o próprio IBRAM (2015, s/p) cita o Decreto No 8.124, de 17 de outubro de 2013 que conceitua:

Rev.Cad.Comun. Santa Maria, v.20, n.3, art 5, p.100 de 123, set/dez.2016 
IX - Museu - instituição sem fins lucrativos, de natureza cultural, que conserva, investiga, comunica, interpreta e expõe, para fins de preservação, estudo, pesquisa, educação, contemplação e turismo, conjuntos e coleções de valor histórico, artístico, científico, técnico ou de outra natureza cultural, abertos ao público, a serviço da sociedade e de seu desenvolvimento.

Em diversos casos, os museus tiveram que se modificar para que pudessem receber mais visitantes advindos do turismo. Sobre essa mudança causada pelo turismo, Castro (2007, s/p) corrobora, avaliando que:

Em uma tentativa de sistematização geral do tipo de relacionamento existente entre a cultura e o turismo, percebe-se que nos últimos anos tem crescido de forma relevante a oferta de produtos culturais, como resultado de dois fatores principais: a revitalização dos museus nas últimas décadas e o fato da 'indústria turística' estar oferecendo mais programas integrados com produtos culturais.

Portanto, pode ser dito que os museus veem se reinventando ao passar dos anos. Para com isso, atrair cada vez mais visitantes, e satisfaze-los.

Alguns dos resultados dessa reinvenção dos museus, são os museus virtuais, onde o visitante em muitas vezes tem a possibilidade de interagir com o acervo.

\section{Museu virtual}

O formato antigo de museu, reiterando o tópico anterior, vem se tornando insuficiente para seus visitantes. Assim, para o ICOM' (1986, apud. BARRETTO, 2000, citado por, LIMA et.al. s/d, s/p), os museus podem ser definidos como:

[...] uma instituição permanente, sem finalidade lucrativa, a serviço da sociedade e do seu desenvolvimento, aberta ao público, que realiza pesquisas sobre a evidência material do homem e do seu ambiente, adquire-a, conserva-a, investiga-a, comunica e exibe-a, com a finalidade de estudo, educação e fruição.

O Museu Virtual pode ser frequentemente uma extensão de um muInternational Council of Museums 
seu físico, ou ainda, pode ser um museu totalmente e exclusivamente virtual com todo seu acervo disponível apenas de forma virtual.

Porém, deve-se ter muito cuidado ao se divulgar algo como Museu Virtual, pois, por ser um novo conceito ainda é muito confundido. Como analisa Muchacho (s/d, s/p):

Muitas vezes o que é intitulado de museu virtual é apenas um site informativo sobre as actividades do museu, esquecendo as potencialidades e novas perspectivas das TIC face aos museus, em especial na forma como expõem os objectos e comunicam com o público.

Em resumo, os museus virtuais ainda são algo novo, e podem ser confundidos facilmente com sites informativos utilizados por museus reais. Além disso, tais museus podem ser totalmente virtuais, ou podem também ser copias de locais físicos que foram virtualizados, resultado da necessidade dos museus se reinventarem e de visitantes cada vez menos satisfeitos com apenas observar as obras através de vitrines.

Tais museus podem ser acessados atualmente através de dois tipos de mídia: CD-ROM e internet. Portanto, valesse estudar a relação entre turismo e mídia.

\section{Turismo e mídia}

Do ponto de vista informal, o turismo é conceituado como a ação de viajar a lazer, já para a $\mathrm{OMT}^{2}$ (2003), numa concepção mais detalhada, ela o define como "Movimento de pessoas a lugar diverso do qual habite por tempo inferior a 360 dias, desde que esta não realize atividades econômicas".

Porém, alguns autores discordam dessa definição, Rabahy (1990, apud. XAVIER, 2007, p. 20) defende que o turismo:

É o movimento migratório, até um limite máximo de 90 dias, seja internacional ou nacional, sem propósito de longa permanência e sem exercício de uma atividade ou profissão remunerada. $\mathrm{O}$ objetivo pode ser por prazer, comercial ou industrial, cultural, artístico ou científico. Não inclui viajantes que juridicamente entram no país, como é o caso dos passageiros de avião que per- 
manecem nos aeroportos, seja por escala ou conexão ou outras linhas aéreas, nem o movimento unicamente de fronteiras.

Todavia, Cunha (1997, apud. DINIS, 2005, p. 13 - 14) ressalva que:

O turismo abrange todas as deslocações de pessoas quaisquer que sejam as suas motivações, que obriguem ao pagamento de prestações e serviços durante a sua deslocação e permanência temporária fora da sua residência habitual superior ao rendimento que, eventualmente, aufiram nos locais visitados.

Percebe-se que as principais discordâncias dos autores em relação ao conceito de turismo apresentado pela OMT em 2003 são em relação ao tempo e motivos da viagem. Portanto, observa-se que a OMT (2008, apud. PANTELESCU, 2012, p. 31) em um conceito mais atualizado, define o turismo como:

Tourism is a social, cultural and economic phenomenon which entails the movement of people to countries or places outside their usual environment for personal or business/professional purposes. These people are called visitors (which may be either tourists or excursionists; residents or non-residents) and tourism has to do with their activities, some of which imply tourism expenditure. International tourism comprises inbound tourism plus outbound tourism, that is to say, the activities of resident visitors outside the country of reference, either as part of domestic or outbound tourism trips and the activities of non-resident visitors within the country of reference on inbound tourism trips.

Destarte, ao passar dos anos a OMT passou de uma definição mais conservadora e limitada, para uma mais abrangente. Entretanto, ainda nos dias atuais, não existe um conceito formulado sobre o turismo. É perceptível que a grande quantidade de conceitos, não apenas o da OMT, como de outros autores e Organizações ou Instituições, tem evoluído ao passar dos anos.

\section{O que é mídia?}

Diante de poucas pesquisas sobre o tema no campo do Turismo, facilmente tornasse notável que o termo mídia está associado de forma leiga e errônea aos profissionais que a utilizam, por exempla: a imprensa.

Rev.Cad.Comun. Santa Maria, v.20, n.3, art 5, p.103 de 123, set/dez.2016 
Porém, o termo mídia diz respeito ao meio utilizado para o repasse das notícias e informações (NIELSEN, 2002). Certamente, a mídia na verdade é o veículo de comunicação entre os noticiadores e os noticiados. Dentro desta mesma linha de pensamento, Castells e Cardozo (2005, p.28) expõem que:

Uma característica central da sociedade em rede é a transformação da área da comunicação, incluindo os media. A comunicação constitui o espaço público, ou seja, o espaço cognitivo em que as mentes das pessoas recebem informação e formam os seus pontos de vista através do processamento de sinais da sociedade no seu conjunto.

A mídia se divide basicamente em duas: a Mídia Impressa, que pode ser definida por todos os materiais impressos, como jornais, revistas, dentre outros; e a Mídia de Massa que segundo Dizard (2000, p. 23) "mídia de massa, historicamente, significa produtos de informação e entretenimento produzidos e padronizados, distribuídos a grandes públicos através de canais distintos". Dentro destes dois tipos estão contemplados os jornais, revistas, outdoor, rádios, TV, a internet, entre outros.

É necessário salientar que a mídia sofreu mudanças ao longo dos anos e, atualmente, sua maior influência se dá através da TV e da Internet. E também se faz necessário reconhecer o grande avanço da internet em todo o mundo. Ela talvez se torne o principal meio de comunicação mundial em alguns anos. Neste sentido, Perinotto (2014, p.241) salienta que “[...] através da internet o indivíduo está sendo bombardeado por novas informações, novos conhecimentos e comportamentos".

Observa-se que a Mídia Informacional ${ }^{3}$ vem ganhando a cada dia mais importância na sociedade. Devido a este fato, é de suma importância tomar muito cuidado nas informações que são divulgadas, isto é, se faz necessário verificar sempre a veracidade e atualidade das informações.

Já a internet é uma mistura de diferentes tipos de mídia, a fim de se ter uma melhor interação com seus usuários. Conforme o pensamento de Morais et. al. (2012, p.58) "a web criou uma linguagem de comunicação

3 "Comunicação com caráter informativo [...] a mídia informacional atua através de jornais televisivos, revistas, jornais impressos e pela internet" (PEREIRA e SIVEIRO, 2013, s/p).

Rev.Cad.Comun. Santa Maria, v.20, n.3, art 5, p.104 de 123, set/dez.2016 
própria, de apelo visual, com uma mistura intrigante de características de mídia impressa e televisiva. E isso mudou definitivamente a cara da Internet.". Também Miranda (s/d, p.10), expõe que "a Internet constitui um importante canal de distribuição e comunicação, que fornece um meio poderoso e direto pelo qual se pode interagir com os consumidores de forma global, onde quer que o mesmo esteja". Deste modo, faz-se necessário estudar a importância da internet como fonte de informações para os turistas.

\section{A internet no desenvolvimento do turismo}

A mídia tem um papel muito importante no desenvolvimento turístico das localidades, já que é através dela que, possivelmente, tornar o destino conhecido no mundo todo. Nesse sentido, Miranda (s/d. p.3) expõe que:

Com a evolução das tecnologias nos últimos anos, principalmente aquelas ligadas à Internet, observou-se que diversos setores da economia, inclusive aos ligados ao turismo, tiveram que se integrar a estas evoluções. Neste sentido, diversas empresas do trading turístico como agências, hotéis e principalmente empresas aéreas entraram na rede de forma direta ou não para ter uma possível redução de custo, como também um novo canal de comunicação.

O suporte que a internet oferece aos usuários é multifacetado, e bem variado. Para o turismo, essa ferramenta é muito relevante, Cooper (2001, apud. ANJOS et.al. 2006, p. 30) ressalta que:

A internet, como suporte da informação, oferece ainda uma infraestrutura multimídia, capaz de colaborar para os atores vinculados à prática do turismo. Ela dá mais poder ao consumidor, através do fornecimento dirigido de produtos que atendem às suas necessidades individuais, diminuindo, assim, a distância entre o turista e a destinação/oferta, de uma forma interativa e flexível.

Muitos autores defendem que a internet contribui para a atividade, um exemplo é Santos (2002, p. 76) que diz: 
A Internet tem, sem dúvida, grande contribuição neste novo cenário das tecnologias da informação e sua interface com o turismo. As diversas qualidades e opções que a rede oferece podem ser utilizadas de inúmeras maneiras, no sentido de desenvolver melhores formas de promoção, distribuição e gerenciamento da atividade turística.

A internet nos dias atuais, tem se tornado a principal ferramenta de busca no turismo, atualmente, as pessoas buscam desde a compra de passagens às dicas de lugares agradáveis, a fim de formular seus próprios roteiros, fugindo dos pacotes de viagem e preferindo roteiros mais flexíveis.

É possível identificar a crescente busca por informações através da internet, pelo menos, é isso que aponta o estudo realizado pelo Ministério do Turismo (2010, apud. GUERRA et.al. 2014, 411):

\begin{tabular}{|l|l|l|l|l|l|l|l|}
\hline FONTE DE INFORMAÇÃO & $\mathbf{2 0 0 4}$ & $\mathbf{2 0 0 5}$ & $\mathbf{2 0 0 6}$ & $\mathbf{2 0 0 7}$ & $\mathbf{2 0 0 8}$ & $\mathbf{2 0 0 9}$ & $\mathbf{2 0 1 0}$ \\
\hline Internet & 26,8 & 19,9 & 24,4 & 27,6 & 27,5 & 30,1 & 30,9 \\
\hline Amigos e parentes & 37,3 & 43,1 & 39,7 & 38,4 & 30,7 & 30,8 & 28,4 \\
\hline Viagem corporativa & - & 16,9 & 19,5 & 17,9 & 17,1 & 15,6 & 16,0 \\
\hline Agência de Viagens & 11,3 & -- & 8,5 & 8,6 & 13,6 & 12,2 & 14,5 \\
\hline Guias turísticos e impressos & - & 8,4 & 7,5 & 5,8 & 6,5 & 7,3 & 6,2 \\
\hline Feiras, eventos e congressos & -- & -- & - & 1,3 & 1,6 & 1,4 & 1,4 \\
\hline Folders e brochuras & -- & 1,1 & 0,4 & 0,5 & 0,4 & 0,3 & 0,4 \\
\hline Outros & 24,6 & 10,6 & 4,5 & 3,1 & 2,5 & 2,3 & 2,2 \\
\hline
\end{tabular}

Figura 1: Fontes de Informação para a Organização de Viagem.

Adaptado de: Brasil (2010)

Outros teóricos argumentam que é impossível se planejar uma viagem sem a utilização da internet, já que ela tem se tornado o principal meio de intermediação entre fornecedores e consumidores. De mesmo modo, Marsílio (2012, s/p) defende que:

Atualmente é impossível pensar agências de viagens e turismo sem a utilização da internet, porque essas a utilizam como principal meio de trabalho, para acessar e distribuir informações de forma eficaz. A internet integra a comunicação de dados entre a empresa, clientes e fornecedores, por exemplo, as empresas acessam os sistemas de reservas dos fornecedores como companhias aéreas, hotéis, locadoras de carros, dentre outros.

Já, segundo uma pesquisa realizada pelo Google (2009, apud. GUERRA et.al. 2014) com internautas foi apontado que $89 \%$ dos internautas entrevistados utilizam pelo menos uma fonte on-line para comprar algum tipo de produto relacionado ao turismo, como reservas de hotel, passagens

Rev.Cad.Comun. Santa Maria, v.20, n.3, art 5, p.106 de 123, set/dez.2016 
aéreas, aluguel de carros e viagens em cruzeiros.

Enquanto a importância da internet no processo de busca de informações, Pinho (s/d, apud. MAGALDI, 2010, p. 20) afirma que:

\begin{abstract}
A internet evidencia um incontornável potencial informativo e comunicativo tanto em questões de rapidez de circulação, número de pessoas que atinge e áreas geográficas que abarca; e devido às suas características de imaterialidade, instantaneidade e multimídia, democratiza o acesso à informação e a determinados tipos de bens, facilita a comunicação entre pessoas e instituições e universaliza as oportunidades, eliminando as barreiras espaciais, geográficas e temporais.
\end{abstract}

Através do estudo feito pelo Ministério do Turismo (BRASIL, 2010), nota-se o modo como à internet superou os outros meios de comunicação em relação à busca de informações. Se configurando como uma mídia em constante crescimento e cada vez mais empresas veem seu enorme potencial, as empresas do setor turístico tendem a buscar clientes navegantes na rede, já que é possível constatar com base nos conceitos apresentados, que a internet atualmente é o principal meio de busca de informações e, consequentemente, é onde a maior parte das informações está concentrada e de livre acesso.

Como se pode notar, os autores citados acima reconhecem a importância da internet no desenvolvimento do turismo e, sobretudo, os mesmos acreditam que essa relação só tende a crescer, elevando o turismo a outros patamares num futuro bem próximo. Portanto, é perceptível que a internet está se tornando o principal meio de intermédio entre clientes e empresas no setor turístico, tornando obsoleto o uso de espaços físicos pelas agências.

\title{
Procedimentos metodológicos
}

Para a constituição deste trabalho utilizou de uma pesquisa bibliográfica dos temas estudados, como, museu virtual, turismo, mídias, entre outros. Além de se realizar um estudo de caso de um Museu Virtual já estabelecido, com o objetivo de melhores respostas sobre como a experiência de visitação pode influenciar os visitantes. Para isto, utilizou-se o Museu Virtual de Ouro Preto. Após a visitação, os entrevistados deveriam responder o questionário, o qual buscava averiguar os relatos a respeito das

Rev.Cad.Comun. Santa Maria, v.20, n.3, art 5, p.107 de 123, set/dez.2016 
experiências proporcionadas pelo Museu Virtual de Ouro Preto.

Nesta pesquisa, os sujeitos foram alguns alunos pré-selecionados do Curso de Bacharelado em Turismo da Universidade Federal do Piauí. O questionário foi disponibilizado para estes alunos através do sistema de comunicação oficial da UFPI, o SIGAA ${ }^{4}$, durante o período de 22/01/2016 a 29/01/2016. Sendo toda a entrevista realizada através deste meio de comunicação, além disso, durante as aulas, os alunos selecionados foram estimulados à realizar o tour virtual e posteriormente responder o questionário. Estas respostas obtidas serviram para analisar a potencialidade dos museus como ferramentas de comunicação turística.

No que diz respeito ao objeto de estudo desta pesquisa trata-se da virtualidade proporcionada pelos museus virtuais, que apesar de serem estudados a mais de 10 anos, ainda existem poucos autores que tratam do tema, sobretudo, se procurar essas referências desses museus como ferramentas de comunicação. Por este motivo, esta pesquisa tem natureza de caráter exploratório adotando uma análise de conteúdo dos dados quali-quantitativos.

Segundo Denker (1998, p.124) a pesquisa exploratória:

Procura aprimorar idéias ou descobrir intuições. Caracteriza-se por possuir um planejamento flexível envolvendo em geral levantamento bibliográfico, entrevistas com pessoas experientes e análises de exemplos similares. As formas mais comuns de apresentação das pesquisas exploratórias são as pesquisas bibliográficas e o estudo de caso.

Além de possuir caráter exploratório a pesquisa também se caracteriza por fazer uma análise de conteúdo dos dados obtidos através da aplicação de questionários semiestruturados com perguntas abertas e fechadas. Assim, portanto, Pádua (2004, p.72) afirma que "os questionários são instrumentos de coletas de dados que são preenchidos pelos informantes, sem a presença do pesquisador".

Já, a respeito da análise, uma das utilizadas foi a de conteúdo. Pelo fato de se possuir respostas com caráter qualitativo dentre os resultados, para Bardin (2012, p.167):

4 Sistema Integrado de Gestão de Atividades Acadêmicas

Rev.Cad.Comun. Santa Maria, v.20, n.3, art 5, p.108 de 123, set/dez.2016 
A análise de conteúdo constitui um boom instrumento de indução para se investigar as causas (variáveis inferidas) a partir dos efeitos (variáveis de inferência ou indicadores; referências no texto), embora o inverso, predizer os efeitos a partir dos factores conhecidos, ainda não esteja ao alcance das nossas capacidades.

Com a análise de conteúdo dos dados e a pesquisa bibliográfica buscou-se entender como o Museu Virtual pode servir para a comunicação turística das localidades do qual está inserido. Para melhor ilustrar isso, foi utilizado o Museu Virtual de Ouro Preto. Os entrevistados puderam visitar o museu e logo após responderam um questionário a respeito dessa experiência, ou seja, realizou um estudo de caso com um museu virtual já estabelecido em busca de um melhor entendimento de como os Museus Virtuais podem servir como ferramenta de comunicação e divulgação. Segundo Yin (2015, p.2):

A pesquisa de estudo de caso, é uma das várias maneiras de se realizar uma pesquisa em ciências sociais. [...] A pesquisa de estudo de caso seria o método preferencial em comparação aos outros em situações nas quais (1) as principais questões da pesquisa são "como?" ou “porque?"; (2) um pesquisador tem pouco ou nenhum controle sobre eventos comportamentais, e (3) o foco do estudo é um fenômeno contemporâneo (em vez de um fenômeno completamente histórico).

O instrumento de coleta de dados foi elaborado através do Google For$\mathrm{ms}^{5}$ e aplicado via internet. Sendo assim, considera-se que o ambiente da pesquisa é a internet. Para Castro (2006, p.21): "A Internet democratizou o acesso à informação, permitindo que os países adotassem metodologias e tecnologias similares, independentemente de seu estágio de desenvolvimento".

O questionário buscava informações sobre temas diferentes e se utilizam de diferentes sujeitos da pesquisa. Para Cervo et.al. (2007, p.53) "o questionário é a forma mais usada para coletar dados, pois possibilita medir com mais exatidão o que se deseja.".

O Museu Virtual de Ouro Preto (Ver Figura 2) foi escolhido pelo fato de ser um museu já consolidado, além de apresentar uma forma de navega-

5 Ferramenta do Google de cria formulários e questionários para pesquisa.

Rev.Cad.Comun. Santa Maria, v.20, n.3, art 5, p.109 de 123, set/dez.2016 
ção bem simplificada e fornecer informações sobre tudo que está exposto no seu tour virtual. Desta forma, avalia-se que o museu de Ouro Preto representa, de forma positiva, o segmento dos museus virtuais.

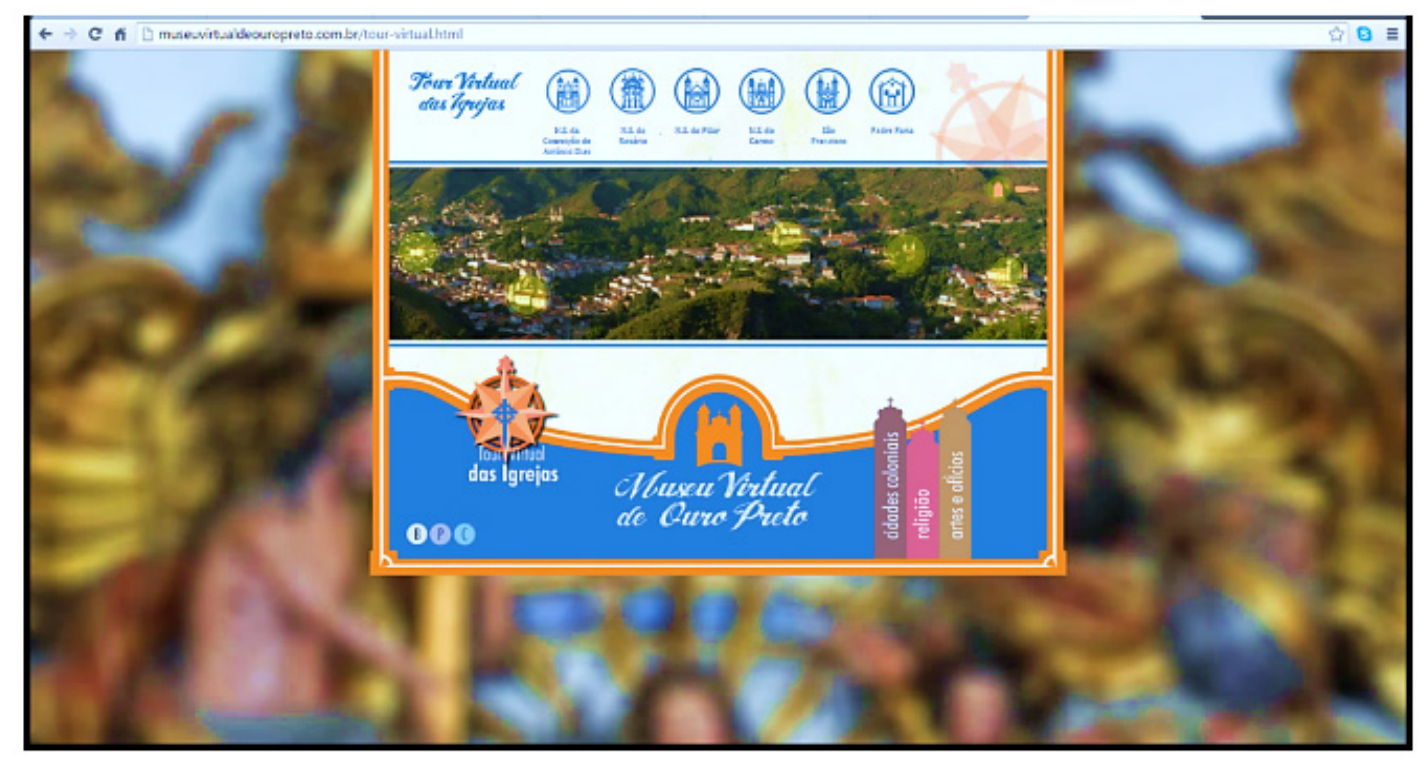

Figura 2: Pagina Inicial do Tour Virtual das Igrejas de Ouro Preto Fonte: http://museuvirtualdeouropreto.com.br/tour-virtual.html

Como já foi dito anteriormente, nesse questionário, os sujeitos da pesquisa foram os alunos do curso de Bacharelado em Turismo da Universidade Federal do Piaui - UFPI, Campus Ministro Reis Velloso, mais especificamente, os que estavam cursando as disciplinas de Tecnologias da Informação e Comunicação e Tópicos Emergentes em Turismo. O processo de escolha desses sujeitos, deu-se por diversos motivos dentre eles, podem ser citados alguns em específico como o fato dos sujeitos serem alunos de um curso de Graduação em Turismo. Soma-se a isso, os conteúdos estudados nestas duas disciplinas.

Os alunos da disciplina de Tecnologias da Informação e Comunicação foram escolhidos principalmente por esta disciplina estar ligada mesmo que indiretamente ao objetivo de estudo desta pesquisa, já que é nessa disciplina que são estudados e discutidos os temas a respeito do impacto da tecnologia nos dias atuais, assim, especificados na ementa desta disciplina:

Conceitos de tecnologias da informação e da comunicação. O impacto das tecnologias da informação e da comunicação na Sociedade. Introdução aos Sistemas de Informação. Hardware e Software. Noções de bancos de dados e de informações. In-

Rev.Cad.Comun. Santa Maria, v.20, n.3, art 5, p.110 de 123, set/dez.2016 
ternet. Comércio eletrônico (E-business). Ciberconsumidor. Os impactos das tecnologias da informação e da comunicação nas Organizações Turísticas. Aplicabilidade dos princípios e das ferramentas das tecnologias da informação e da comunicação no gerenciamento operacional e estratégico das Organizações Turísticas. (UFPI, s/p, 2009).

Sendo assim, os alunos desta disciplina têm conhecimento o suficiente para agregar valor a esta pesquisa.

Já, a escolha dos alunos da disciplina de Tópicos Emergentes em Turismo, deu-se por esta disciplina ser no último componente curricular obrigatório do curso, em que os alunos ainda possuem aula presencial teórica. Desta forma, esta é a última disciplina não optativa de todo o curso. Esses alunos, além de já terem passado pela disciplina de Tecnologias da Informação e Comunicação, estão a bem próximos de serem Bachareis em Turismo, ou seja, já tem todo um conhecimento obtido através de todos os 4 anos de curso, o que torna-os aptos para responder esta pesquisa.

Os respectivos acadêmicos foram convidados a visitar o Museu Virtual de Ouro Preto. Fazendo o tour virtual das igrejas e, posteriormente, responder o questionário a respeito dessa visitação para que pudessem visitar o museu à vontade e fazer suas próprias conclusões. Segundo Bamberger e Tal (2007, apud. EICHLER e DEL PINO, 2007, s/p):

[...] a aprendizagem promovida "ao ar livre" (informal) é diferente daquela que se realiza em sala de aula (formal) e, nesse sentido, a aprendizagem despreocupada e natural em museus acentua a manifestação da aprendizagem em contextos pessoais. Assim, com toda a oportunidade de escolhas, os estudantes associam sua visita as suas próprias experiências de vida e aos seus conhecimentos prévios, mesmo quando as atividades guiadas raramente apontam a isso.

Assim sendo, buscou-se entender de que forma o Museu Virtual pode servir como uma ferramenta de comunicação e promoção turística dos destinos do qual está inserido.

Todos os dados obtidos através dos questionários durante as duas etapas, foram tabulados com a ajuda do software de computador Microsoft Oficce Excel 2007, ultilizando o recurso “tabelas dinâmicas" para gerar todas a tabelas desta pesquisa em que nas perguntas fechadas analisou-se as frequências em que determinas respostas se repetiam; enquanto nas

Rev.Cad.Comun. Santa Maria, v.20, n.3, art 5, p.111 de 123, set/dez.2016 
abertas analisou-se os relatos que se assemelham, isto é, onde obteve-se concenso entre as opinões dos sujeitos da pesquisa.

\section{Museu virtual como motivador para o turista}

A Tabela 1 apresenta um dado importante - 14 entrevistados consideraram a visita ao museu uma experiência positiva; e nenhum dos entrevistados considerou esta experiência negativa. Desta forma, todos os entrevistados, após visitar o Museu Virtual de Ouro Preto, consideraram que esta foi uma experiência positiva, o tour virtual, os textos de ajuda dentre outros, agradou todos os visitantes.

\section{Como você considera esta experiência?}

\begin{tabular}{l|r}
\hline Positiva & 14 \\
\hline Negativa & 0 \\
\hline Total geral & 14
\end{tabular}

Tabela 1: A experiência obtida

Fonte: Pesquisa Direta

Sabe-se o quanto pode ser importante para o turista ter uma experiência positiva a respeito do lugar antes de decidir em visitá-lo. Portanto, é correto afirmar que no caso do Museu Virtual de Ouro Preto, a experiência positiva acarreta em motivação para o turista visitar a cidade. É o que mostra a Tabela 2.

\begin{tabular}{|l|r|}
\hline Você sentiu-se motivado em visitar o destino após esta experiência? \\
\hline Sim & $\mathbf{1 4}$ \\
\hline Não & $\mathbf{0}$ \\
\hline Total geral & $\mathbf{1 4}$ \\
\hline
\end{tabular}

Tabela 2: Sentiu-se motivado em visitar o destino

Fonte: Pesquisa Direta

A Tabela 2 mostra que 14 entrevistados afirmaram que se sentiram motivados a visitar Ouro Preto após a experiência obtida através do Museu Virtual de Ouro Preto. De acordo com os resultados da pesquisa, avalia-se que o museu pode sim servir como motivador para o turista, pois posteriormente ao tour virtual das igrejas, $100 \%$ dos entrevistados sem contestação sentiram interesse em visitar a cidade. Nesse sentido, Gândara (2003, TOREZANI, 2007, p.63) avalia que:

Os meios de comunicação social evocam lugares, ambientes, culturas, viagens, que provocam nos consumidores um desejo de experimentá-los por si mesmos. A indústria turística cresceu

Rev.Cad.Comun. Santa Maria, v.20, n.3, art 5, p.112 de 123, set/dez.2016 
de forma espetacular não somente devido aos avanços tecnológicos, mas também por causa do aumento do alcance dos meios de comunicação.

Deste modo, avaliar o museu virtual como ferramenta de comunicação é também avaliá-lo como um motivador para o turista em conhecer o destino.

Do ponto de vista de turismólogo (a), você acredita que o museu virtual de ouro preto possa servir como ferramenta de comunicação turística e divulgação dos atrativos da cidade?

\begin{tabular}{|l|r|}
\hline Sim & 14 \\
\hline Não & 0 \\
\hline Total geral & 14 \\
\hline
\end{tabular}

Tabela 3: Acredita que o museu virtual de ouro preto possa servir como ferramenta de comunicação turística e divulgação dos atrativos da cidade

Fonte: Pesquisa Direta

O Museu Virtual de Ouro Preto oferece ao visitante um tour virtual por todas as igrejas da cidade, ou seja, oferece uma visitação virtual de lugares que realmente existem na cidade. A Tabela 3 demonstra, indubitavelmente, que todos os entrevistados afirmaram que o museu pode servir como uma ferramenta de comunicação turística e divulgação dos atrativos da cidade. Para Torezani (2007, p. 21):

A comunicação, de um modo geral, constitui uma forma de representação do chamado real e a comunicação turística surge dotada de elementos a serem divulgados, através das mensagens midiáticas, como os destinos turísticos, com seus atrativos e serviços.

Portanto, através dos resultados obtidos, o Museu Virtual de Ouro Preto serve como meio de divulgação dos atrativos da cidade, no caso, as igrejas.

Já a Tabela 4 apresenta que na opinião de $100 \%$ dos entrevistados, a visita ao museu virtual pode servir como fator decisório para o turista na tomada de decisão em visitar a cidade ou não, deste modo, evidencia-se que esta visita pode influenciar o turista que pretende visitar a cidade.

\begin{tabular}{|l|r|}
\hline $\begin{array}{l}\text { Você acredita que essa experiência possa ser um fator decisório para o turista na hora } \\
\text { de tomar a decisão de visitar ou não a cidade? }\end{array}$ \\
\hline Sim & 14 \\
\hline Não & 0 \\
\hline Total geral & 14 \\
\hline
\end{tabular}

Tabela 4: Essa experiência possa ser um fator decisório para o turista

Fonte: Pesquisa Direta

Rev.Cad.Comun. Santa Maria, v.20, n.3, art 5, p.113 de 123, set/dez.2016 
O Museu Virtual de Ouro Preto oferece uma experiência de visitação bem completa aos seus visitantes, além do tour virtual, mostra textos informativos sobre as igrejas e as obras contidas nelas. Assim, perguntou-se aos entrevistados se na opinião deles, o museu virtual pode servir como um complemento da visitação, ou seja, se a experiência de visitação virtual e a visitação de fato a cidade se complementam.

A Tabela 5 apresenta que $100 \%$ dos entrevistados afirmam que o museu virtual pode sim servir como complemento da visitação.

\begin{tabular}{|l|r|}
\hline $\begin{array}{l}\text { Na sua opinião, o museu virtual pode servir como um complemento da visitação para o } \\
\text { turista? }\end{array}$ \\
\hline Sim & 14 \\
\hline Não & 0 \\
\hline Total geral & 14 \\
\hline
\end{tabular}

Tabela 5: O museu virtual pode servir como um complemento da visitação para o turista Fonte: Pesquisa Direta

Conforme o raciocínio e estudo de Marty e Twidale (2004, apud. MUCHACHO, s/d, p. 15244 - 1545) apresentam a usabilidade dos museus virtuais características específicas, dentre elas que:

Nos museus virtuais que existem como um complemento ao museu físico o interface é criado com o intuito de complementar o espaço físico. Os visitantes virtuais consultam toda a informação que pretendem antes ou depois da visita física, onde puderam encontrar informações extras. A visita virtual é na realidade um complemento à visita física.

Sabendo que o Museu Virtual de Ouro Preto oferece um tour virtual pelas igrejas da cidade, isso quer dizer que é um complemento de igrejas que realmente existem e dispõe de informações de tudo que é apresentado ao visitante. Deste modo, Lepouras et.al. (2004, apud. EICHLER e DEL PINO, 2007, s/p) sugere que:

[...] o termo Museu Virtual pode ser usado sem uma relação direta com a ideia de realidade virtual, ou seja, pode ser utilizado, também, para descrever exibições interativas e não apensas indicar a aplicação de sistemas gráficos imersivos em 3D.

Embora esses locais físicos não ofertem visitas guiadas, o turista tem a oportunidade de ver as obras, porém, não tem informações a respeito de

Rev.Cad.Comun. Santa Maria, v.20, n.3, art 5, p.114 de 123, set/dez.2016 
sua história, origem, etc. Pode-se ressaltar que como constatado na pesquisa, o museu virtual oferece uma experiência complementar a visitação real.

A respeito da experiência obtida pelos entrevistados ao visitar o Museu Virtual, o Quadro 1 apresenta o que foi relatado na pesquisa. Em que se pode avaliar que para os entrevistados essa experiência foi positiva.

Percebe-se que em alguns relatos, as informações disponibilizadas sobre as obras mereceram a atenção dos visitantes. Este é um ponto positivo encontrado no museu. Tais informações propiciam que o turista tenha uma visão ampla/completa das igrejas, onde além de poder vê-las através do museu, pode também conhecer um pouco mais de sua história.

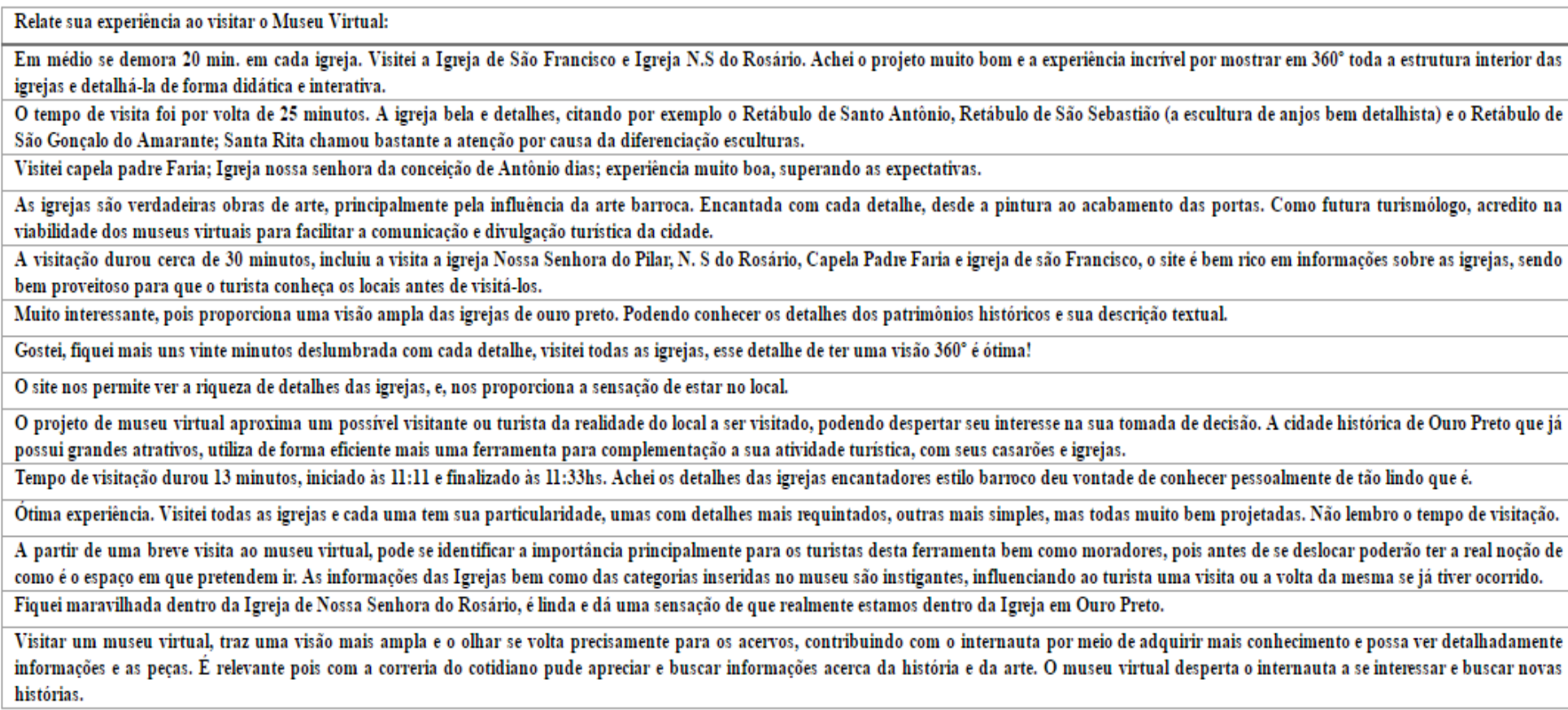

Alguns entrevistados também relataram a importância da visitação virtual, já que o turista pode "estar" nas igrejas antes de visitá-las, ou seja, o turista pode "ir" (virtualmente/digitalmente) até Ouro Preto sem sair de casa, podendo ter certa noção de como é a cidade. Para melhor entendimento, alguns relatos que tratam dessa "sensação de estar no local" foram isolados e categorizados, que estão apresentados no Quadro 2. 


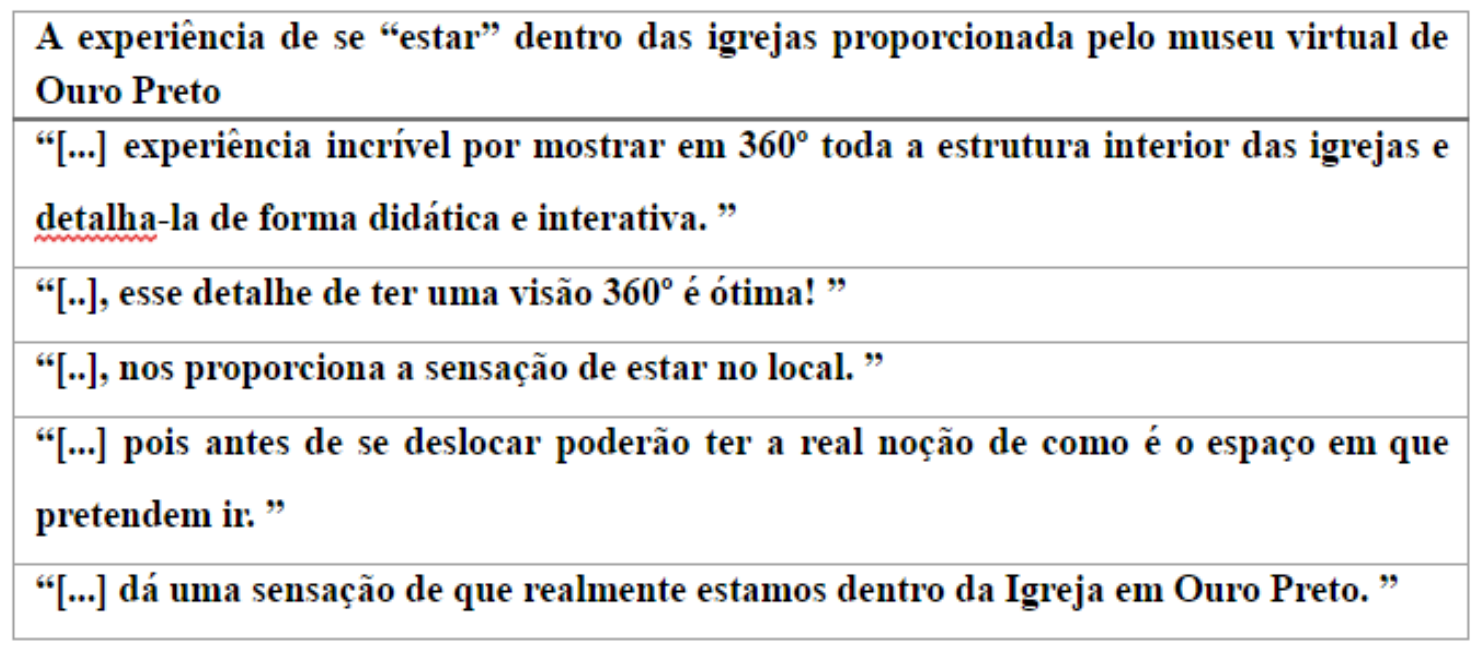

Fonte: Pesquisa Direta (2015)

Segundo o Quadro 2, 5 sujeitos expuseram que o Museu Virtual através da "visão $360^{\circ}$ " da igreja, proporciona ao visitante a sensação de se estar no local; e faz esse visitante ter uma "real" noção do seu destino. Além disso, Coelho (2010, p.19) afirma que:

Uma visita virtual é uma simulação de um espaço, real ou não, que permite ao utilizador interagir e navegar nesse ambiente através de um computador ou outra tecnologia que o permita. Tem como objetivo criar a sensação de se estar a "viver" um ambiente virtual como se fosse físico. Graças a tecnologias recentes e à constante evolução destas, cada vez existem mais visitas virtuais com maiores interações e funcionalidades.

De modo geral, de acordo com o que foi relatado pelos sujeitos da pesquisa, para o turista o Museu Virtual pode despertar nele a curiosidade, ou até mesmo pode fazer com que o turista vislumbre como é estar dentro da igreja, despertando assim seu imaginário para que o desperte interesse em conhecer de fato a cidade.

\section{O museu virtual como ferramenta da comunicação turísti-} ca

Sabe-se que o museu virtual oferece além do tour $360^{\circ}$ pelas igrejas de Ouro Preto, informações valiosas sobre esses lugares visitados e seus acervos. O Museu Virtual é uma fonte de informações confiável em que os turistas têm livre acesso a essas informações. Para Costa (2009, apud.

Rev.Cad.Comun. Santa Maria, v.20, n.3, art 5, p.116 de 123, set/dez.2016 
COELHO, 2010, p.10) a disciplina que trabalha com esses museus virtuais, é a cibermuseologia e ela pode ser definida como:

[...] a área que estuda os processos de preservação, comunicação e disseminação dos conteúdos de um museu através do uso das tecnologias de informação e comunicação presentes na Internet, e que visam contribuir para a virtualização do museu e do seu património.

Enquanto Muchacho (s/d, p. 1524) corrobora avaliando que:

O museu, como importante meio de comunicação, tem de aproveitar todo este desenvolvimento comunicacional e tecnológico, no sentido de satisfazer as novas correntes da museologia que se debruçam cada vez mais sobre o papel do museu na sociedade atual. As novas mídias e em particular a internet são um instrumento precioso no processo de comunicação entre o museu e o seu público.

Baseado nisso, é possível considerar que o Museu Virtual é um meio de comunicação. Assim sendo, é através dele que a informação será repassada aos visitantes. E para que essa informação seja passada da melhor maneira se tem a preocupação de quais conteúdos devem ser transmitidos aos turistas, para que assim a mensagem seja repassada de forma que ocorra uma experiência positiva nos seus visitantes.

Então, sabendo que a comunicação turística diz respeito à promoção dos lugares e que para os turistas a informações tem influência no seu processo de decisão em visitar, ou não, o possível destino, é correto afirmar que o Museu Virtual pode ser utilizado como uma ferramenta de promoção dos destinos, já que oferece aos visitantes várias informações sobre os locais visitados.

Já a respeito dessas informações, Sheller (2016, s/p) ao explanar sobre seu trabalho juntamente com outro pesquisador, diz que "[...] we have information that is coming to us on screens and we're using that to navigate through urban space.", ou seja, para a autora, as informações recebidas podem gerar uma sensação de "estar" em determinado local de maneira real.

Portanto, cabe-se analisar como a virtualidade pode servir para a divulgação dos museus e dos locais o qual estão inseridos. $\mathrm{E}$, de acordo com o exposto, e com os relatos do Quadro 2, avalia-se que, no caso do museu

Rev.Cad.Comun. Santa Maria, v.20, n.3, art 5, p.117 de 123, set/dez.2016 
virtual de Ouro Preto, essa virtualização pode ser bastante vantajosa.

\section{Considerações finais}

Os museus virtuais buscam ter uma melhor interação com o visitante que os museus físicos. Esses museus virtuais dispõem de imagens, vídeos, entre outras coisas, portanto, proporcionam ao visitante diversas informações da localidade que podem ser utilizadas facilmente durante o planejamento de uma viagem.

Estas informações contam para que durante o planejamento da viagem, o potencial turista seja influenciado a conhecer ou não determinada localidade. Sendo assim, estas informações têm papel importante na tomada de decisão do turista/consumidor.

Sabe-se que os Museus Virtuais, podem ser "cópias" virtuais de lugares físicos, como no caso do museu virtual de Ouro Preto. Entretanto, estas cópias virtuais, muitas vezes, podem ser um complemento do real, onde apresentam informações mais detalhadas sobre o local, que muitas vezes não estão disponíveis ou não estão tão acessíveis aos visitantes do lugar físico. Sendo assim, o meio virtual interage com o físico, tornando-o mais completo, mais perceptível.

Valesse ressaltar também que os Museus Virtuais oferecem uma experiência de visitação "livre" em que o visitante pode "entrar" a hora que quiser, ou "ir" onde desejar no museu utilizando apenas alguns clicks.

Esse modo de visitação pode ser bastante positivo, causando uma experiência agradável nos visitantes.

Portanto, de acordo com os resultados obtidos, nota-se que os Museus Virtuais podem servir como ferramentas da comunicação turística, mesmo que indiretamente, já que o seu processo de criação não se deu por este motivo, deu-se da necessidade de interligar visitante-obra de uma melhor maneira possível, para que assim haja uma melhor comunicação entre o acervo e seus apreciadores.

Outro fator importante, é que alguns museus virtuais, assim como o de Ouro Preto, já proporcionam ao visitante o tour virtual, onde o visitante tem sensação de "estar" no local pessoalmente. Essa sensação de estar no lugar é causada pela forma que as informações atingem o cognitivo dos visitantes, ou seja, como estas informações chegam ao visitante, e como ele as utiliza para navegar pelo museu de uma forma bem "real".

Rev.Cad.Comun. Santa Maria, v.20, n.3, art 5, p.118 de 123, set/dez.2016 
É importante o estudo do real potencial desta virtualidade, sendo que essa virtualização pode ser vantajosa para as localidades. Através desse processo podem ser resguardadas as memórias, o patrimônio material e imaterial destas localidades, além de poder repassar de forma bem simples estas informações por meio dos museus virtuais que estão sempre "abertos" na internet.

Diante dos fatos arrolados, os museus virtuais podem ser considerados ferramentas de comunicação e promoção dos destinos, mesmo que de forma indireta, já que podem despertar o interesse de possíveis visitantes; e que também dispõe de informações que facilitam a comunicação e diálogo entre esse a pessoa que está planejando viajar e a localidade. 
CADERNOS DE COMUNICAÇÃO

UNIVERSIDADE FEDERAL DE SANTA MARIA

\section{REFERÊNCIAS}

ANJOS, E. S. et. al. Novas tecnologias e turismo: um estudo do site Vai Brasil. Disponível em: <http://www.spell.org.br/documentos/download/20949> Acesso em 17. Maio. 2015

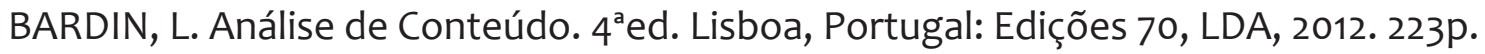

BRASIL, Instituo Brasileiro de Museus. Política Nacional de Museus. Disponível em: <https://www.museus.gov.br/wp-content/uploads/2010/01/politica_nacional_museus. pdf> Acesso em 20. Jan. 2016

CASTELLS, M. A galáxia da internet: reflexões sobre a internet, os negócios e a sociedade. Rio de Janeiro: Zahar. 234p.

CASTELLS, M.; CARDOZO, G. A Sociedade em Rede: Do Conhecimento à Acção Política. Disponível em: <http://www.egov.ufsc.br/portal/sites/default/files/anexos/a sociedade_em_rede_-_do_conhecimento_a_acao_politica.pdf> Acesso em 30. Jan.2016

CASTRO, A. L. S. Museu e turismo: uma relação delicada. In Encontro Nacional de Pesquisa em Ciência da Informação, 8, 2007, Salvador. Anais Eletrônicos. Salvador: UFBA, 2007. Disponível em: <http://www.enancib.ppgci.ufba.br/artigos/DMP--257.pdf> Acesso em 30. Jan. 2016

CASTRO, R. C. F. Impacto da Internet no fluxo da comunicação científica em saúde. Disponível em: <http://www.scielo.br/pdf/rsp/v40nspe/30623.pdf> Acesso em 30. Jan. 2016

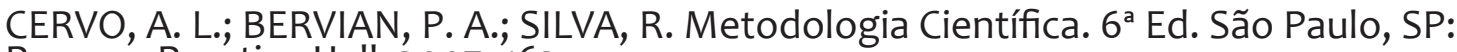
Pearson Prentice Hall, 2007. 162p.

COELHO, P. R. P. S. A construção de visitas virtuais 3d: o caso do museu de Aveiro. 2010. 59p. Dissertação (Mestrado em Comunicação Multimédia) Universidade de Aveiro, Aveiro, 2010.

DENCKER, A.F.M. Métodos e técnicas de pesquisa em turismo. São Paulo: Futura, 1998. 286p.

DINIS, S. M. O ecoturismo: um instrumento para o desenvolvimento sustentável?. 2005. 117p. Dissertação (Mestrado em Desenvolvimento e Cooperação Internacional) Universidade Técnica de Lisboa, Lisboa, 2005.

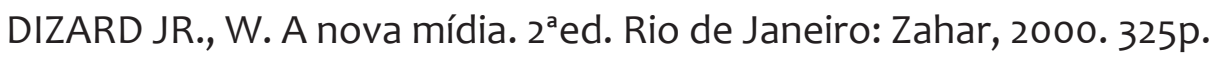

EICHLER, M. L.; DEL PINO, J. C. Museus virtuais de ciências: uma revisão e indicaçõos técnicas para o projeto de exposições virtuais. In: Novas Tecnologias na Educação, V.5 $\mathrm{N}^{\circ} 2,2007, \mathrm{~s} / \mathrm{p}$.

GUERRA, A. C.; GOSLING, M.; COELHO, M. F. Redes Sociais: um jornal on-line como fonte de informação especializada em turismo. Disponível em: <http://www.spell.org.

Rev.Cad.Comun. Santa Maria, v.20, n.3, art 5, p.120 de 123, set/dez.2016 
LIMA, L. P.; GUIMARÃES, C. J.; CARMO, T. D. M. Gestão pública em museus e a atividade turística. In Encontro Paranaense de Pesquisa e Extensão em Ciências Sociais Aplicadas, 7, 2011, Campo Mourão. Anais Eletrônicos. Campo Mourão: Faculdade Estadual de Ciências e Letras de Campo Mourão, 2011. Disponível em: <http://www.fecilcam.br/ anais/vii_enppex/PDF/turismo/12-turismo.pdf> Acesso em 30. Jan. 2016

MAGALDI, M. B. Navegando no Museu Virtual: Um olhar sobre formas criativas de manifestação do fenômeno Museu. 2010. 253p. Dissertação (Mestrado em Museologia e Patrimônio) - Programa de Pós-Graduação em Museỏlogia e Patrimônio, Universidade Federal do Estado do Rio de Janeiro, Rió de Janeiro, 2010.

MARSÍLIO, M. O Impacto da Internet Nas Agências de Viagens e Turismo: Um Estudo Bibliométrico. In Seminário de Pesquisa em Turismo do Mercosul, 7, 2012, Caxias do Sul. Anais Eletrônicos. Caxias do Sul: Universidade de Caxias do Sul, 2012. Disponível em: <http://www.ucs.br/ucs/tplvSeminTur\%20/eventos/seminarios_semintur/semin_ tur_7/gto8/arquivos/08/01_20_26_Marsilio> Acesso em 19/05/2015 às 22:37

MIRANDA, C. S. A Internet como ferramenta de comunicação no Turismo: um estudo exploratório da utilização de e-mails pelo trading em Ribeirão Preto e seus impactos no Turismo local. In: Rẻvista Turismo \& Pesquisa, N.3, 2004, p. 1-11.

MORAIS, I. A. L.; SILVEIRA, C. B. M. Museu e turismo cultural: análise do perfil dos turistas culturais do museu do homem do Nordeste (Pernambuco/Brasil). In: Revista Iberoamericana de Turismo, V.1, N.2, 2011, p. 49-60.

MUCHACHO, R. (2005): "Museus virtuais: A importância da usabilidade na mediação entre o público e o objecto museológico". In: Biblioteca on-line de Ciências da comunicação, V.1, 2005, p. 1540-1547.

MUCHACHO, R. (2005): "O Museu Virtual: as novas tecnologias e a reinvenção do espaço museológico". In: Biblioteca on-line de Ciências da comunicação, V.1, 2005, p. 579-583.

NIELSEN, C. Turismo e Mídia. Trad. Edite Sciulli. São Paulo: Contexto, 2002. 319p.

OMT, Organização Mundial do Turismo. Disponível em: <http://www2.unwto.org/> Acesso em: 10. Maio. 2015.

PÁDUA, E. M. M. Metodologia da Pesquisa: Abordagem teórico-prática. $11^{\text {a }}$ ed. Campinas, SP: Papirus, 2014. 124p. :

PANTELESCU, A. M. Trends in International Tourism. In: Cactus Tourism Journal, V.3, 2012, p. 31-35.

PEREIRA, E. H.; SIVIERO, M. L. A mídia e suas publicidades. Disponível em: <http:// docslide.com.br/documents/1-emc-5003-tecnologia-e-desenvolvimento-equipe-eduardo-hopner-pereira-mateus-lopes-siviero-professores-walter-antonio-bazzo-maio20131-a-midia-e-suas.html> Acesso em 20. Maio. 2015

PERINOTTO, A. R. C. Circulação de imagens fotográficas de paisagens rurais: comuni-

Rev.Cad.Comun. Santa Maria, v.20, n.3, art 5, p.121 de 123, set/dez.2016 
cação, marketing e atração de demanda. In: Caderno de Comunicação, V.18, N.1, 2014, p. 229-243.

SANTOS, G. E. O. Internet e Destinações Turísticas: análise de "sites" de turismo dos governos estaduais brasileiros. In: Turismo em Análise, N.13, 2002, p. 74-87.

SANTOS, R. J.; HONORATO, M. J.; SILVA NETO, E. V. Turismo, Museus e Cultura: notas sobre estratégias e ações em nível federal, 2003 - 2011. In Seminário de Pesquisa em Turismo do Mercosul’, 7, 2012, Caxias do Sul. Anais Eletrônicos. Caxias do Sul: Universidade de Caxias do Sul, 2012. Disponível em: <http://www.ucs.br/ucs/tplVSeminTur\%20/ eventos/seminarios semintur/semin_tur_7/gt02/arquivos/02/12_Santos_Honorato_Viana> Acesso em 30. Jan. 2016

SHELLER, M. For society and technology, the future is hybrid. Disponível em: <http:// en.forumviesmobiles.org/video/2016/02/02/society-and-technology-future-hybrid-mimi-sheller-3120> Acesso em 2. Fev. 2016

TOREZANI, J. N. Estado e Comunicação: Análise do portal de turismo do governo da Bahia sobre a atividade turística ém Illhéu. In Congresso Brasileiro de Ciências da Comunicação, 29, 2006, Brasília. Anais Eletrônicos. Brasília: Universidade de Brasília, 2006. Disponivel' em: <http://www.intercom.org.br/papers/nacionais/2006/resumos/ R0248-1.pdf> Acesso em 20. Maio. 2015

UFPI, Universidade Federal do Piauí. Proposta Pedagógica do Curso de Graduação em Turismo. Parnaíba - PI. Disponível em: <http://www.leg.ufpi.br/subsiteFiles/cc/arquivos/files/turismo_cmrv.pdf > Acesso em 11. Fev. 2016

XAVIER, M. L. P. A expansão hoteleira na cidade de Santo André após o ano 2000. 2007. 159p. Dissertação (Mestrado em Administração) - Programa de Pós-Graduação em Administração, Universidade Municipal de São Caetano đo Sul, São Caetano dó Sul, 2007.

YIN, R. K. Estudo de caso: Planejamento e métodos. $5^{\text {a }}$ ed. Porto Alegre, RS: Bookman, 2015. 271p. 


\section{Resumo sobre autores:}

Brendo Rodrigues dos Santos

Bacharel em Turismo pela Universidade Federal do Piauí UFPI, email: brendorsantos5@gmail.com

André Riani Costa Perinotto

Doutor em Ciências da Comunicação - UNISINOS/RS. Professor Adjunto do Curso de Bacharelado em Turismo da UFPI (Universidade Federal do Piauí - Brasil) Campus Parnaíba/PI. Professor do Mestrado em Gestão de Negócios Turísticos da UECE. E-mail: perinotto@ufpi.edu.br

RECEBIDO EM: 20/06/2016

ACEITO EM: 30/08/2016 